\title{
Does the team think?
}

\author{
Stephen Hancocks OBE \\ Editor-in-Chief
}

Anything is possible. The older that one gets the less one expects to be surprised by that which the world throws up; but the more one is. I may pretend to have invented that observation and name it 'Hancocks' Law'. So, I wouldn't really be surprised if there was still one or more dental practices in the UK whose inhabitants didn't know that all members of the dental team now have to be registered with the GDC and that we have recently passed the first anniversary of it happening.

However, over 4,000 Dental Care Professionals (DCPs) did not pay their annual retention fee (ARF) either at all, or in time for the 31 July 2009 cut off point and so have been removed from the register. It would be less surprising to discover that some of these are still practising, perhaps unknown to their employers that they are working illegally. From a total of just under 56,000 this is a small percentage but the GDC is silent about what it does to follow up on these nonpayers and, rather like cars without insurance, it is somewhat unfair on the rest of us who have to contribute to the resultant shortfall.

So what does the team think after its first year of being a whole and legal entity? Does it think that the ARF is worth the money? The question is often asked as to what the GDC does with the cash and the latest GDC Gazette provides an answer. ${ }^{1}$ It tells us that the Council's income in 2008 was £23 million including $£ 19$ million in 'fees' and that its expenditure was $£ 21.5$ million; so that's helpful. In terms of its stated aim of 'protecting patients', and by using the estimate that about half the population visit the dentist in a given year it works out that it costs every patient slightly under a pound each or every adult about 50p. I know that we the registrants pay the ARF but ultimately we are paid by the patient; so are they getting value for money?

\section{PROTECTING PATIENTS HAS HIDDEN COSTS}

The cost doesn't end there though. Additionally, there is the business of Continuing Professional Development (CPD) which absorbs both time and money. Resources have to be put into creating CPD programmes, events and publications and even if these are 'free' at the point of participation the costs still exist albeit hidden either by sponsorship derived from the price of goods and services or more directly from fees, membership dues and subscriptions. Ultimately, again, the funding for all this comes un-itemised from the patient. What does the team think about CPD? Broadly there is an acknowledgement that the principle is good but that 'they' (and the 'they' is variously the employing dentist, the NHS, the GDC or any other potential target) should be providing more opportunities at little or no cost for lowly paid team members.

Next comes indemnity, another element of the package required for the true professional to function. What does the team think of this? The team seems bemused, confused and slightly angry by the need, or rather the apparent lack of need given that it has never previously been required, the cost (again) and the bewilderment that this is what being professional really means. There is more than a lingering whiff of the king's new clothes about the matter of being a professional. So the message is clear but obscured, protecting patients the GDC's way increases the costs of oral health. Costs that are set to rise even higher in future years as the resources required to set-up and run revalidation will be immense, relying as any true system of quality must on human judgement, which requires skilled, knowledgeable and experienced individuals who do not come cheap.

So, does the team think of itself as a team? Even with some of the issues from above rankling, for the most part probably the answer is 'yes', although dental technicians, 560 of whom were removed from the register for non-payment, manifestly still feel out of it; not invited to the party. Turning the question around, does the team think the unthinkable - that we should reconsider registering DCPs and return to the old days of wild west employment from the street, no defined standards for team members, no CPD, no professional status and no annual registration fees? I suspect not but I also believe that this is only the beginning of a journey and that there are some hurdles to be taken along the route. If the true status of the team is to be apparent, extolled and appreciated then it also has to have investment, a degree of openness and greater acknowledgement than has been fully forthcoming to date. As the newly created, non-elected GDC members take up their mantles, as the professionals in oral care go about their daily business and as patients take their seats in surgeries throughout the land there needs to be a much greater awareness of what the team thinks if it is to function as quite another team of visionaries originally thought it should.

1. GDC Gazette. Autumn 2009. London, GDC. www.gdc-uk.org 